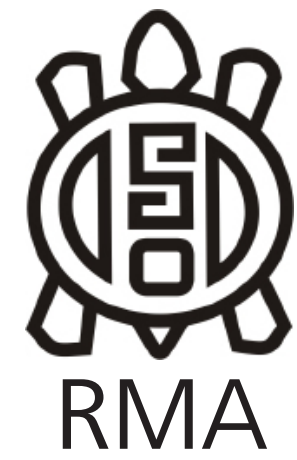

Dossier

\title{
De historias y signos de época. Prólogo al dossier
}

\author{
Of stories and signs of the time. Foreword to the dossier
}

\author{
Romina C. Spano*, Julián Salazar**, Nurit Oliszewski*** \\ ${ }^{*}$ Centro Regional de Investigaciones Científicas y Transferencia Tecnológica de La \\ Rioja (CRILAR) - CONICET. Instituto de las Culturas (IDECU) UBA - CONICET, Museo \\ Etnográfico "Juan B. Ambrosetti". E-mail: romina.spano@gmail.com \\ ** Instituto de Estudios Históricos, CONICET, Universidad Nacional de Córdoba. \\ E-mail: juliansalazar@ffyh.un.edu.ar
}

****Instituto Superior de Estudios Sociales (ISES) UNT-CONICET. E-mail: nuritoli@yahoo.com.ar

Palabras Clave: Primer Milenio d.C., Área Surandina, Arqueología, XX CNAA.

Keywords: First Millennium AD, Southandean Area, Archaeology, XX CNAA.

Ojalá que vivas tiempos interesantes (antigua maldición china)

\section{Introducción: nuestra historia ... ¿ya un signo de época?}

El dossier que aquí presentamos es producto del simposio Historias locales y Signos de Época II: Paisajes, viviendas y objetos del primer milenio de la Era en los Andes del Sur, realizado en el marco del XX Congreso Nacional de Arqueología Argentina (XX CNAA), durante el mes de julio de 2019 en la ciudad de Córdoba. Dicho espacio surgió de la necesidad de intercambio de experiencias y la pasión que tenemos quienes investigamos las primeras sociedades aldeanas en esta parte de los Andes meridionales. El encuentro dio continuidad a otro realizado en Tucumán en 2016, con motivo del XIX CNAA. En esta ocasión a las zonas que tradicionalmente fueron conocidas por los desarrollos aldeanos del primer milenio d.C. se sumaron otras donde este período y estas sociedades permanecían hasta cierto punto soslayados. De este modo, a las presentaciones de casos de las Cumbres Calchaquíes, la Sierra del Aconquija, las Sierras y Valles de Catamarca, la Puna y el Piedemonte de Jujuy, se adicionaron estudios de caso de la Quebrada de Humahuaca, de la provincia de Santiago del Estero y de Chile Central. Esta diversidad geográfica de la casuística deja entrever que lejos de agotarse, la temática sigue despertando interés.

Escribimos este prólogo desde nuestras propias historias locales y personales, en tiempos que nos encuentran atravesados por un evento que será ineludible cuando se relate la historia del tercer milenio d.C. La pandemia que recientemente ha sido calificada por Ignacio Ramonet como hecho social total, en tanto fenómeno mundial y simultáneo que altera y conmociona las relaciones sociales, las instituciones y los valores (Ramonet 2020), es un marco que, pues sujetos situados, recorrió nuestras reflexiones y miradas sobre los relatos de antaño que aquí presentamos, y nos hizo volver sobre el planteo de signos de época que trazamos hace unos años (Spano y Salazar 2017). Para Lévi-Strauss el concepto de hecho social total aludía a la capacidad de síntesis de cada acción individual de integrar los aspectos sociológicos -sincrónicos-, históricos -diacrónicos-, físicos, fisiológicos y psíquicos que caracterizan al ser humano (González Castillo 2005). Un hecho social total, entonces, expresa el contexto más amplio de prácticas e instituciones en las cuales se desarrolla, así como un modo dado de entender el mundo. En tiempos en los que la casa resulta el ámbito en torno al cual se desarrollan las interacciones entre personas a distintas escalas y de diversa índole (familiar, económica, recreativa, ritual, etc.), es inevitable observar bajo la lente humanística los modos de construir (o deconstruir) el espacio doméstico, las percepciones sobre el "afuera" y el "adentro", y también sobre lo público y lo privado; las modificaciones en la experiencia cotidiana del transcurrir del tiempo.

Estas reflexiones tomaron forma bajo las circunstancias en las que encaramos las redacciones, lecturas, revisiones y reflexiones compartidas que implicó la elaboración de este dossier: nos encontraron inmersos en eternas reuniones virtuales, lidiando con el trabajo en casa con hijos, hijas, padres y madres bajo nuestro 
cuidado, o en situación de aislamiento estricto, bajo la inevitable lluvia de información sobre la pandemia que contextualizó nuestras experiencias individuales en la adversidad colectiva. ¿Cómo escindirse del presente al mirar el pasado? ¿Cómo no mirar con otros ojos los lazos comunitarios, los conceptos de grupos de parentesco y/o co-residencia, las definiciones territoriales, la organización témporo-espacial, los rituales de despedida y la construcción de memorias? Tiempos propicios para volver sobre nuestros planteos acerca de las historias locales y los signos de época.

\section{Paisajes, viviendas y objetos}

Sign o' the times mess with your mind Hurry before it's too late (Prince, Sign o'the times)

Dos fueron los ejes que nos convocaron en tanto autores, coordinadores y relatores: las historias locales y los signos de época. ¿Son estos conceptos contrapuestos, o complementarios? Estas dos laxas categorías se construyeron como una invitación a pensar de manera integradora y mediadora sendas miradas que necesariamente entran en tensión cada vez que formulamos narrativas arqueológicas en algún período de la historia prehispánica, y especialmente cuando nos aproximamos al mundo de las aldeas tempranas. El sustrato del pensamiento tradicional en arqueología, y en especial de la arqueología del temprano o del formativo, estuvo signado por la búsqueda de "fósiles guía" que marcaran una época, que permitieran ubicar culturas, entidades socioculturales o sistemas en determinados casilleros, ya sean de la historia cultural o de la evolución social. Esos elementos clave podrían posteriormente ser utilizados en otras subregiones para desentramar las secuencias cronológicas o descubrir el tipo social que subyacía a los materiales.

Esas categorías, que permitieron identificar con una notable precisión las primeras experiencias aldeanas en casi todo el NOA, empezaron a diluirse junto con su época, a deshilacharse en múltiples historias locales que una a una comenzaron a volverse más relevantes en sí mismas, abriendo un amplio horizonte a nuevos casos, distintas temporalidades y sobre todo a un mundo dinámico, improvisado, diverso y cambiante, que había tendido a cubrirse bajo el manto más estabilizado de una articulación sistémica entre producción, sedentarismo y nuevas tecnologías. El signo de la nueva época pasó a ser su inexistencia.

Las tensiones entre posiciones estructuralistas o sistémicas y los enfoques situados y locales dejaron a los debates sobre "esto" que estudiamos (que no sabemos si llamar Temprano, Formativo, Modo de Vida Comunitario Agrocéntrico, Campesinado, Primer Milenio D.C, o Cultura " $\mathrm{X}$ ") en una dicotomía difícil de zanjar. Perder de vista que hay tendencias, que hay elementos compartidos, que hay procesos que se dan en una gran cantidad de regiones en momentos similares y bajo condiciones similares puede ser tan contraproducente como tratar de aplicar de manera homóloga un esquema que dé cuenta de algunas de esas tendencias en todas las poblaciones y microrregiones. Bajo la convicción de que estas dos instancias reflexivas son mutuamente enriquecedoras reunimos a este colectivo de colegas que desde distintas ópticas, materiales y localidades, integraron manos de artesanos con arcillas y formas de construir paisajes, restos vegetales con maneras de habitar viviendas, o de transformarlas en ejes articuladores de la identidad a escalas amplias, entre muchos otros fenómenos que definieron un momento tan particular para las comunidades originarias del norte de nuestro país.

La organización de los trabajos que conforman el dossier sigue dos criterios: el geográfico y el temático. A continuación, presentamos una breve reseña valorativa de cada uno de ellos.

Constanza Taboada se adentra en las razones que subyacen al aparente silencio arqueológico del primer milenio d.C. en el área del río Salado, Santiago del Estero. Mediante una exhaustiva revisión de archivos, registros visuales inéditos y colecciones, y bajo una mirada historiográfica, la autora pone el foco en la constitución y uso de categorías, con énfasis en las distintas denominaciones dadas a las piezas de alfarería grabada/incisa. También evalúa la incidencia de factores ambientales y de las propiedades del registro arqueológico para buscar las razones de la escasez de sitios, integrando datos de sus propias investigaciones. La discusión acerca de la utilización acrítica de la denominación "Las Mercedes" en las clasificaciones cerámicas, con su consiguiente asociación a una misma entidad sociocultural extendida en todo Santiago del Estero en tiempos tempranos, es una muestra de cómo los contextos específicos y las historias locales tienen mucho que aportar en la construcción de los signos de época.

Lidia García nos presenta una necesaria síntesis acerca de las ocupaciones humanas en la microrregión de Azul Pampa situada en la quebrada de Inca Cueva (Jujuy) durante el lapso temporal 3000-1000 A.P. Esta quebrada se ha convertido en uno de los sitios emblemáticos para el estudio del poblamiento inicial del NOA por lo que el análisis aquí presentado -el proceso de cambio hacia una sociedad productora de alimentos- cobra especial importancia. Se muestra la manera de habitar en esta época que abarcó ocupaciones complementarias entre cuevas/aleros y sitios a cielo abierto así como una economía mixta que incluyó a las tradicionales caza y recolección, al pastoreo (estrategia básica local) pero también a la agricultura.

El trabajo de Natalia Petrucci y Romina Spano aborda una 
historia local desde una perspectiva arqueo-etnobotánica que evalúa las relaciones entre seres humanos y plantas en una dimensión multi-escalar poniendo en juego al espacio doméstico, al espacio aldeano y al espacio regional. De este modo y partiendo del estudio del registro arqueobotánico, construyen un relato acerca del modo de vivir de un grupo aldeano que habitó a principios del primer milenio d.C. en Soria 2, en el sudeste del valle de Yocavil (Catamarca). Esta historia local trasciende el mero análisis de las plantas tanto alimenticias como rituales y utilitarias, que de por sí es sumamente valioso, para abarcar la manera de relacionarse entre personas que pertenecían a un mismo núcleo familiar o a grupos distantes. Es decir que nos muestra cómo ciertas prácticas que fueron transversales a diferentes grupos pueden a la vez delinear una historia local y constituirse en signos de época.

El trabajo de Valeria Palamarczuk, Cecilia Raíces Montero, Natalia Petrucci, Catriel Greco, Cristina Molina, María Cristal García y Valeria Castiglioni refiere a una época clave y poco conocida para las primeras sociedades aldeanas: la de finales del primer milenio d.C. Nos ofrece una imagen de los ámbitos domésticos en El Colorado, sur del valle de Yocavil (Catamarca). El diseño arquitectónico -una pequeña unidad doméstica de tipo dispersa- nos habla de una historia local, ya que difiere de los modos de construir conocidos para la región. En cambio, la técnica de acabado de superficie de las cerámicas mediante peinado, apunta a un signo de época dado que la misma era asociada excluyentemente al segundo milenio d.C. Sin embargo, su registro contextualizado invita a reflexionar acerca del origen de las innovaciones tecnológicas y la perduración y generalización de las prácticas de producción en el tiempo.

Nurit Oliszewski y Eugenia Di Lullo utilizan un diseño arquitectónico particular, que ha caracterizado a las primeras experiencias aldeanas del norte del Sistema del Aconquija y del sur de las Cumbres Calchaquíes, para atravesar escalas analíticas, tanto espaciales como sociales. Considerando el patrón constructivo de entornos domésticos, replicado en estructuras situadas en la localidad de la Quebrada de Los Corrales, proponen la modalidad en la que se construyen vínculos familiares, supra-domésticos, comunitarios y multi-comunitarios en una extensa región. Todo este análisis, que involucra también otros tipos de configuraciones espaciales más allá de las residenciales, permite reflexionar sobre los signos de época y dar trascendencia al estudio arqueológico de lugares, espacios y paisajes.

Vanesa Beatriz Juarez, Lucas Pereyra Domingorena, Clarisa Otero y María Beatriz Cremonte aportan una buena síntesis de las evidencias arqueológicas de los últimos siglos del primer milenio en la Quebrada de Humahuaca, época prácticamente desconocida, especialmente por la localización de los asentamientos del período, soterrados bajo los cimientos de poblaciones actuales como la de Tilcara. Dicha particularidad obliga a integrar heterogéneas y dispersas evidencias que fueron construidas por múltiples colegas en trabajos de rescate. Esta dificultosa pero necesaria tarea logra integrarse a través de meticulosos estudios de prácticas alfareras, es decir los modos de hacer y consumir cerámica. Las reflexiones acerca de la procedencia de las vasijas así como de sus características performativas que habilitan cierta escala de consumo, permiten generar una idea dinámica de este particular momento de la historia prehispánica en valles y quebradas.

Los estudios ceramológicos son explorados también desde la novedosa perspectiva de la traceología por Matías Gramajo Bühler y Jaume García Rosselló. Observando macro-trazas en una muestra de alfarería de la Quebrada de Los Corrales, reconstruyen las técnicas de modelado de las vasijas para aproximarse al saber hacer local. Este prometedor estudio propone entender aspectos tecnológicos como modo de observar estructuras sociales e ideológicas, las cuales no se entienden como constructos superestructurales materializados en las distintas fases que recorre la arcilla hasta convertirse en vasija (o en fragmentos) sino como actualizaciones prácticas que se reproducen en la materia cada vez que la misma se transforma.

Francisco Franco nos presenta los avances en el conocimiento de la materialidad del sitio El Sunchal, en el valle de Anfama (Tucumán), también desde la línea de los estudios tecnológicos alfareros. Su aporte se centra en la caracterización de las materias primas empleadas para la elaboración de objetos cerámicos en contextos domésticos, y la identificación de posibles fuentes de arcillas y arenas. Bajo la perspectiva teórica de la arqueología de la práctica, el autor apunta a delinear las elecciones tecnológicas de quienes elaboraron las vasijas halladas en El Sunchal en distintos momentos del lapso estudiado. Se trata de un aporte valioso al corpus de información de base disponible para el área valliserrana, y constituye a la vez un nuevo capítulo en la construcción de la antigua historia local de Anfama.

Los artículos que conforman el dossier atraviesan diversidad de zonas geográficas, perspectivas para mirar e interpretar la materialidad y clases de objetos, lugares y relaciones. Luego de su lectura, se torna necesario un espacio de reflexión y síntesis integradora. A modo de epílogo, el trabajo de Julián Salazar nos invita a mirar(nos) en nuestro(s) pasado(s) reciente(s) en tanto sujetos productores de conocimiento a lo largo de los últimos quince años de arqueologías del primer milenio d.C., en un recorrido ameno y no por ello menos riguroso de los factores que atravesaron la construcción del pasado pretérito. Problemáticas y líneas de evidencia seguidas, perspectivas teóricas, presencia relativa de áreas de estudio y de espacios institucionales de producción de 
ciencia, género, entre otros, son elementos puestos en juego para delinear las maneras de vincularnos con nuestros objetos y sujetos de estudio. Más allá de alcanzar su propósito de balance, el trabajo deviene en un reconocimiento al esfuerzo de quienes intentamos arrojar luz sobre las sociedades del lapso que nos convoca, poniendo en nombres propios las contribuciones e influencias que atraviesan la experiencia subjetiva y colectiva de la investigación.

Como palabras finales queremos expresar que nos fue muy grato transitar todo el proceso que concluye en este dossier: desde la idea de dar continuidad a un simposio que hizo (hace) hincapié tanto en las historias locales como en los signos de época de las primeras sociedades aldeanas de los Andes del Sur; la respuesta que tuvo la convocatoria por parte de los colegas y los debates que allí surgieron; luego la propuesta de reunir las ponencias en un dossier y nuevamente el apoyo de los autores quienes trabajaron a destajo finalizando 2019; la labor de los evaluadores realizada en los primeros meses de 2020 en el contexto de aislamiento obligatorio por lo cual les agradecemos especialmente; el permanente acompañamiento de Roxana Cattaneo en representación de la Revista del Museo de Antropología; y finalmente la edición atravesada como ya dijimos, por la coyuntura mundial que vivimos y que inevitablemente nos afectó e interpeló en lo particular.

Ante la multiplicidad de historias locales referidas, recogemos las palabras de Salazar (en este volumen) para preguntarnos si persiste algo de aquello que hace tiempo se denominó Formativo o Temprano, en tanto signos de época. Una de las respuestas posibles está en el relato multivocal plasmado en las páginas que siguen.

Queda en sus manos este dossier acerca de las primeras sociedades aldeanas, sus signos y sus historias.

Anillaco, Córdoba y Tucumán, 09 de julio de 2020

\section{Bibliografía}

González Castillo, E. (2005). Sobre la noción de hecho social total. Bricolage, 8._https://revistabricolage. wordpress.com/2005/05/01/sobre-la-nocion-de-hechosocial-total/. Acceso: 30/06/2020.

Ramonet, I. (2020). La pandemia y el sistema mundo. Le Monde Diplomatique Edición Cono Sur El Diplo, 4 de mayo de 2020. https://www.eldiplo.org/wp-content/ uploads/2020/04/Ramonet-pandemia-sistema-mundo. pdf. Acceso: 30/06/2020.

Spano, R. C. y Salazar, J. (2017) Historias locales y signos de época: sujetos, objetos y prácticas durante el primer milenio A.D. en el noroeste argentino. Comechingonia. Revista de Arqueología, 21(1), primer semestre de 2017, 5-17. 